\title{
Environmental health community service: Confronting the human resource challenges
}

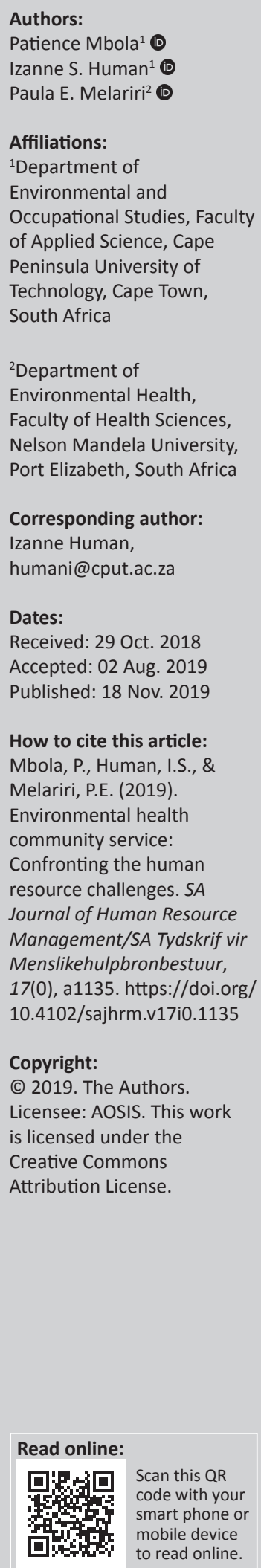

Orientation: The environmental health graduates are required to complete community service before they could be registered as independent practitioners by the Health Professions Council of South Africa. Community service programme serves as the mechanism to recruit healthcare professionals who will improve the provision of equitable and quality healthcare.

Research purpose: The study aimed to explore, identify and describe the factors that had an influence on the effective selection, placement and utilisation of environmental health graduates as well as an evaluation of the effectiveness of community service.

Research approach/design and method: A quantitative, cross-sectional study was conducted using self-administered questionnaires. The study included 24 environmental health practitioners who completed their community service and 10 environmental health practitioners responsible for coordinating community service in the municipal, provincial and national spheres of government in the Eastern Cape province of South Africa during 2013-2016. Purposive sample was drawn from each population. T-test and chi-square test were used to determine the statistical significant differences. The open-ended question responses from the structured questionnaire were qualitatively analysed by an independent coder.

Main findings: The findings revealed major problems regarding the effective implementation of community service that included decreasing number of community service posts, inadequate material resources, lack of induction, inconsistent supervision, and a lack of evaluation of the community service.

Contribution: The study findings suggest important inequalities that should deserve urgent attention. Study concludes by presenting recommendations for the improvement of the community service in the environmental health.

Keywords: community service; environmental health; environmental health practitioner; selection; placement; utilisation.

\section{Introduction}

When a population is exposed to environmental hazards, a relationship is established between the levels of exposure and the health outcomes of that particular population. The linkage created between the status of the environment and human health is therefore termed environmental health $(\mathrm{EH})$. Environmental health is a practice that seeks to protect human health by combating physical, chemical, biological and social threats in the environment. It is the most fundamental public health approach, affecting whole populations and providing a foundation for modern living (South Africa. DoH, 2013, p. 10).

Compulsory community service (CS) for EH practitioners (EHPs) in South Africa was first introduced in 2003 by the Department of Health $(\mathrm{DoH})$. The CS programme is a programme where new EH graduates are expected to serve in public health facilities for the duration of 1 year before being allowed to be registered as independent EHPs with the Health Professions Council of South Africa (HPCSA). The DoH stated that its objective for initiating CS was to ensure the provision of improved health services for all South African citizens. In this process, CS was also expected to provide young professionals with opportunities to develop skills and to acquire knowledge, behaviour patterns and critical thinking that should assist them in their professional development (Reid, 2002, p. 136). Community service should not be perceived as a year of further training; instead, it is a method for recruiting and strengthening the health workforce, specifically in areas where insufficient access to primary healthcare services and systems exists. 
Despite the above-mentioned attempts to introduce CS programmes to health professions, the South African DoH is currently still confronted with the major challenge of providing basic healthcare to all citizens and restoring the historical inequalities in health services delivery (Wranz, 2011, p. 8). The ever-increasing burden of chronic illnesses (e.g. HIV and AIDS and tuberculosis) and the difficulty of recruiting and retaining healthcare professionals in rural and under-served areas complicate the provision of equitable and quality healthcare services (Khan, Knight, \& Esterhuizen, 2009). Community service may not provide a lasting answer to human resource problems in South Africa, or the shortage at the workplace in remote, rural areas, but if human resources are well planned and funded, it may result in the retention of health professionals in underserviced areas.

In 2012, the HPCSA reported that the placement of EH graduates for CS has been a serious challenge for the DoH since 2007, and therefore this challenge has had a negative impact on EH services (EHS) delivery (Cele, Chaka, Mukhola, \& Nemakonde, 2012, p. 5). Moreover, during 2014, the EH students directed a letter to the Honourable Minister of Health regarding the concern with the huge backlog in the CS placement of EH graduates in the country. In this letter, the minister was requested to intervene and act regarding the CS placement backlog that had only affected the EH fraternity within the domain of health since 2007, and ongoing until today. The minister subsequently requested the National $\mathrm{DoH}(\mathrm{NDoH})$ dignitaries to meet with the student coordinators and promised them that the department would be attending to the problem (South Africa. DoH, 2016). Despite the said promises to the student coordinators by the minister, the challenge has been ongoing; this was validated by EHPs who marched to the $\mathrm{NDoH}$ offices in 2016 to deliver a memorandum with the list of demands regarding their dissatisfaction about the improper implementation of CS for EH graduates. The demands that were outlined in the memorandum included addressing the backlog and the placement of graduates, $100 \%$ placements for CS and the provision of bursaries to EH students. Regardless of the above attempts by EHPs and students, the CS challenges continue with no resolution to date.

The aim of this study was to explore, identify and describe the problems associated with the selection, placement and utilisation of the Environmental Health Community Service (EHCS) practitioners, the evaluation of the programme on completion thereof and to use the findings to make recommendations to the $\mathrm{NDoH}$ on how the programme could be improved.

\section{Literature review Introduction}

Within the context of this study, CS will be defined as remunerated healthcare service performed for a mandatory period of 1 year at a public healthcare facility by a newly qualified EH graduate, who is a citizen of South Africa, and intends to register at the HPCSA and practise as an independent EHP in a prescribed category (Harvey \& Pillay, 2006, p. 260; Ndaba, 2013, p. 7). Community service is perceived by Reid and Conco $(1999$, p. 234) to be different from an internship and vocational training, in the sense that it attempts to redress the inequalities of the past.

The idea of CS in South Africa was prompted by the extreme shortage of healthcare practitioners in the country's state facilities because of the 'brain drain' (departure of skilled health professionals from South Africa to other countries) and poor salaries (Harvey \& Pillay, 2006, p. 260). According to the South African DoH, the main objective of CS is to improve access to quality healthcare for all South Africans, especially those in previously under-served areas (South Africa. Department of Health, 2015a). A year of compulsory CS was first introduced in 1998 for all healthcare graduates of medicine, dentistry and pharmacy. Environmental health graduates joined this group in January 2003 (Reid, 2002, p. 135).

Various studies have explored the CS carried out by different categories of health professionals who are registered with the HPCSA. More recently, Hatcher, Onah, Kornik, Peacocke and Reid (2014) conducted a national cross-sectional study to determine the satisfaction levels of doctors and dentists who performed CS. The study found that CS officers who expressed high satisfaction with CS also benefited from professional development, suggesting the need for continued support of CS health professionals in underserved areas. Harvey and Pillay's (2006) survey of the experiences of 52 clinical psychologists serving CS for the first time found that more than $50 \%$ experienced role confusion and difficulties in communicating with patients because of language differences, even though they felt that they made a difference to the communities they served and had gained confidence in their professional ability.

Khan et al.'s (2009) survey of all speech, hearing and language therapists found that less than $50 \%$ were willing to serve in rural institutions after completing CS, referring to the differences in the level of support and supervision, a lack of infrastructural support and resources, as well as language barriers as reasons. All of these studies concluded that, while the CS policy is an important government initiative, there is need for improvement. This article focuses its attention on the implementation of CS in the $\mathrm{EH}$ profession.

\section{Organisational structure of environmental health service delivery in South Africa}

Environmental health service delivery in South Africa is facilitated through a healthcare dispensation that is divided into national, provincial and local spheres of government. It is within these spheres whereby CS is conducted by $\mathrm{EH}$ graduates. 


\section{National sphere of government}

The functions of the NDoH are to promote the health of all South Africans through a comprehensive national healthcare system, focusing on primary healthcare, to provide leadership in formulating health policy, and to assist and encourage provinces to deliver an efficient and successful healthcare service within their respective areas of jurisdiction (De Haan, 1996, p. 3). The office of the National Director of EH is a section within the NDoH. According to Section 9(1) of the National Environmental Health Policy, the said directorate is responsible for facilitating the implementation of $\mathrm{EH}$ programmes and the provision of EHS by provinces according to national priorities (South Africa. Department of Health., 2013). The Directorate:EH within the NDoH therefore provides the technical support to provinces in areas of management and capacity development for the CS programme of EHCS practitioners (South Africa. DoH, 2013, p. 31). The NDoH therefore is the administrator of CS and works together with provincial, municipal and the HPCSA that deals with the registration of health professionals during and after their CS (South Africa. DoH, 2015a).

\section{Provincial sphere of government}

The provincial departments of health are involved in the organisation of CS for EH graduates (Hatcher et al., 2014, p. 2; South Africa. DoH, 2015b, p. 10). The National Environmental Health Policy (2013) also noted the role played by municipalities in delivering Military Health Service (MHS) as a result of devolution (South Africa. Department of Health., 2013). Therefore, the EHCS practitioners work for both the provincial health departments and the municipalities to be exposed to the entire $\mathrm{EH}$ scope of practice as defined by the legislation (South Africa. DoH, 2009).

\section{Municipal sphere of government}

According to section 32 of the National Health Act 61 of 2003, one of the functions of municipalities is to provide MHS. Municipal health services are being rendered to local communities through a healthcare dispensation which is generally known as the District Health System (South Africa. DoH, 2004). The District Health System, which is based on the provision of primary healthcare services, is defined by Tarimo (1991) as:

[A] more or less self-contained segment of the national health system that is comprised of a well-defined population living within a clearly delineated administrative and geographical area, whether urban or rural. (p. 4)

Section 32 (1) of the National Health Act, 2003 (Act 61 of 2003) prescribes that every metropolitan and district municipality should ensure that appropriate municipal services are effectively and equitably provided in their respective areas (South Africa. DoH, 2004).

\section{Community service placement}

The overall responsibility for the placement of EHCS practitioners lies with the Workforce Management: Statutory
Service Placements Directorate in the NDoH (Cele et al., 2012, p. 2; Maseko, 2012, p. 37). The NDoH facilitates the organisation of EHCS, and the provincial health departments arrange the selection and placement of EH graduates for CS. The local sphere of government also provides the platform for the placement of EHCS practitioner because most of the EHS services are offered in that sphere. The South African Military Health Service (SAMHS) also forms part of the institutions that offer CS to the EH graduates (South Africa. DoH, 2015).

\section{Research methodology Research design}

This quantitative, cross-sectional study was conducted using self-administered questionnaires. The design of the questionnaire was based on a review of existing studies concerning CS and public administration literature to review the requirements for the effective selection, placement, utilisation and evaluation of EHCS personnel (Beyers, 2013; Nel et al., 2014; Reid, 2002; Wranz, 2011). The questionnaires for both the EHCS practitioners and the EHCS administrators focused on six sections: Section 1 - Biographical data, Section 2 - Employment data, Section 3 - Graduate selection, Section 4 - Graduate placement, Section 5 - Graduate utilisation and evaluation and Section 6 - Recommendations.

Ethical approval to conduct this study was obtained from the relevant universities' postgraduate studies committee (reference number removed for blind peer review). Permission to conduct this study was obtained from the EC provincial DoH and from relevant municipalities. A pre-test for the questionnaire was conducted, and the population in the questionnaire testing was categorised into two groups: it included one EHP who completed CS and one EHP who was involved in the administration of CS and these two individuals were not included in the study. The purpose of pre-testing the questionnaire was to determine whether (1) conclusions could be drawn from the information gathered, (2) respondents understood the questions correctly and (3) to adjust the study to alleviate any difficulties that could possibly impact on the validity and reliability of the data collection. The questionnaire testing triggered changes with regard to the precise sequence of questions to enhance the participants' understanding. The face validity of this study has also been ensured through the scrutiny of the questionnaires by the researcher and a statistician. Consensus was obtained between the researcher and the coder regarding the one open question in the questionnaire that was qualitatively analysed.

\section{Participants}

The population of this study is categorised into two groups: (1) EHPs (referred to as EHCS practitioners) who completed their CS during 2013-2016 within the EC province of South Africa and (2)EHPs (referred to as EHCSadministrators) who had the responsibility of administering and coordinating 
CS programmes in the national, municipal and provincial spheres of government in the ECP during 2013-2016.

\section{Data collection}

The researcher contacted all potential participants (EHCS practitioners and administrators during 2013-2016) verbally and through an information letter that was sent via email to arrange a suitable time and venue for administering the questionnaires. Consent forms were then emailed to all the participants who agreed to participate in the study. The aim, procedure, risks and possible benefits of the study were described in the informed consent form which was emailed to respondents. Respondents were ensured of confidentiality and that participation in the study was voluntary. Questionnaires were emailed to respondents who consented to participate in the study. Twenty-five EHCS practitioners and 10 EHCS administrators completed the self-administered questionnaires.

\section{Data analysis}

A statistician from the Nelson Mandela University Centre of Statistical Consultation assisted with the analysis of the quantitative data, using Stata 13.1. The data obtained were coded, captured and submitted to the statistician for analysis. The $t$-test and chi-square test were used to determine the statistical significant differences in the quantitative data. Only the comments made in response to the open-ended question in Section 6 of the structured questionnaire were captured and sent to an independent coder for qualitative data analysis.

\section{Ethical consideration}

The ethics clearance reference number is H16-HEAENVIR-001.

\section{Results and discussion Socio-demographics}

In the first phase, a total number of 10 EHPs who were involved in coordinating CS in the EC province, from 2013 to 2016, completed and returned questionnaires by email. These coordinators consisted of six men and four women, eight African, one white and one mixed race, of which seven were married. Job designations ranged from three junior EHPs, one senior EHP, three EHP assistant directors, one chief EHP and two EH managers. Five EHPs were working for the municipal sphere, and five were employed by provincial health districts, of which two were employed by MHS. Five of these administrators obtained a BTech degree, three had a National Diploma, one had a master's degree and one did not reveal his or her highest qualification. The years of experience in the $\mathrm{EH}$ occupation ranged from 4 to 9 years $(40 \%), 19$ to 26 years $(50 \%)$ and 33 years $(10 \%)$.

In the second phase, a total number of $25 \mathrm{EHCS}$ practitioners who were placed in the EC province during 2013-2016 completed and returned questionnaires via email. These participants consisted of eight men (32\%) and 17 women (68\%) who were all single and included 21 African (84\%) and four mixed race $(16 \%)$ individuals. Most respondents were between the ages of 23 and 29, except one, who was 34 years old. Three of the 25 participants indicated that they had been funded by EC provincial bursaries during their studies. Eight participants (32\%) indicated that they were currently unemployed; four (16\%) were employed in the private sector; nine $(36 \%)$ were employed by the MHS; two (8\%) were employed in the provincial health sphere; and the remaining two $(8 \%)$ were employed by the national sphere of health services. Twelve $(36 \%)$ of those who indicated that they were employed also specified that they are working in the EC province.

\section{Selection and placement process}

\section{Experiences of Environmental Health Community Service administrators}

Four (40\%) EHCS administrators indicated that they were not informed or indicated not applicable (N/A) to the receiving of instructions concerning the identification of EHCS vacancies for the selection of EHCS practitioners (Table 1). Three (30\%) of the EHCS administrators indicated that they received comprehensive documentation, explaining the methodology that should be followed in the process of the identification of EHCS posts. Although six of the participants agreed that they were instructed to identify posts for the EHCS programme, some $(n=2)$ were not provided with the guidelines or documentation of how to go about with the process of identifying the posts for the EHCS programme.

One of the EHCS administrators indicated that the selection process of EHCS practitioners was facilitated by the provincial DoH, whereas five administrators indicated that they were not aware of the methods that should be followed to select EH graduates for the EHCS programme, and 20\% (n $=2$ ) of the EHCS administrators indicated that a curriculum vitae is considered as the best method for selection. Regarding the notification for EHCS, one administrator indicated that the $\mathrm{EH}$ graduates were notified in June 2014 to apply for EHCS in 2015, while another administrator indicated that EH graduates were notified in January 2015 to apply for EHCS in 2015. Eight administrators were not aware when the EH graduates were notified to apply; two of the EHCS administrators were requested to identify EHCS posts more than once.

The majority of EHCS administrators $(n=7)$ indicated that their sites of placement for EHCS practitioners were in the urban areas. More than $50 \%$ of administrators $(n=6)$ stated that they were able to place less than $50 \%$ of the students for EHCS in their facilities. Most of the EHCS administrators ( $n=$ 9; 90\%) agreed that the facilities where the EHCS practitioners were placed were notified in advance regarding the date and time of their commencement. All of the EHCS administrators $(n=10 ; 100 \%)$ felt that the placement facilities were sufficiently prepared to receive the EHCS practitioners. 
TABLE 1: Environmental Health Community Service administrators' and practitioners' experiences relating to the selection and placement process.

\begin{tabular}{lll}
\hline Variables & $n$ & $\%$ \\
\hline EHCS administrators ( $\boldsymbol{n}=10$ ) & & \\
Methods of instruction for CS post-identification & 4 & 40 \\
In writing by NDoH & 1 & 1 \\
Verbally by the PDoH & 2 & 2 \\
Not informed & 1 & 10 \\
Other (in a national workshop by NDoH) & 2 & 20 \\
Not applicable &
\end{tabular}

The document that explained the methodology for identification of EHCS posts was provided

Yes

No

I do not know

N/A

No response (missing system)

When (month and year) were the EH graduates notified to apply for EHCS?

June 14

January 15

N/A

I do not know

Missing system (no response)

Were you requested more than once to identify posts for EHCS?

Yes

No

N/A

Missing system (no response)

Main method for selection of EH graduates for EHCS

Curriculum vitae

Selection was made by Eastern Cape Provincial DOH

I do not know

Missing system (no response)

Location of an area where EHCS practitioner was placed

Rural

Urban

Place where your EHCS practitioners conducted their CS

Military Health Service

Metropolitan municipality

District municipality or health District

$\%$

The approximate percentage of stude

sphere of government or facility

Less than $50 \%$

$50 \%-75 \%$

$75 \%-100 \%$

The facility where the EHCS practitioners were placed was informed in advance about the date and time of their arrival

Yes

90

I do not know

110

EHCS practitioners ( $n=25$ )

How were you informed about the selection process for CS?

In writing from $\mathrm{NDoH}$

In writing from $\mathrm{PDoH}$

In writing from my University

Verbally by $\mathrm{NDoH}$

Verbally by university

Other (telephonically by PDoH)

Did you apply more than once for selection?

Yes

No

Indicate the method of your selection for EHCS

Interview

Curriculum vitae (CV)

$\mathrm{CV}$ and interview
TABLE 1 (Continues...): Environmental Health Community Service administrators' and practitioners' experiences relating to the selection and placement process.

\begin{tabular}{lll}
\hline No selection method used & 16 & 64
\end{tabular}

Other

Nature of the area or the facility where I was placed

Rural

Urban

14

Placement facility which I was allocated to conduct EHCS

Military Health Service

Metropolitan Municipality

Health district or municipality

Local municipality

Sub-district

Choice of allocation

First choice

Second choice

Third choice

Fourth choice

Fifth choice

First choice for internship converted into CS

5 for internship converted into CS

Missing system (no response)

I was provided with an appointment letter before I commenced with EHCS Yes

No

The facility was prepared to receive me

Yes

No

I do not know

$13 \quad 52$

$12 \quad 48$

I was provided with an appointment letter before I commenced with EHCS

Yes

No

I was satisfied with the site of my placement

Yes

No

DoH, Department of Health; PDoH, Provincial Department of Health; EHCS, Environmental Health Community Service; NDoH, National DoH; CS, community service.

The experiences of EHCS administrators indicated a lack of consistency in the selection process of $\mathrm{EH}$ graduates, and a general lack of shared knowledge among themselves regarding the organisational process of EHCS. This was revealed by the fact that some of these participants, although involved in the EHCS organisation, were not all aware of the processes that ought to be followed towards the selection of EH graduates for EHCS.

\section{Experiences of Environmental Health Community Service practitioners}

Fifty-two per cent of the EHCS practitioners $(n=13)$ indicated that they were notified in writing by the $\mathrm{NDoH}$ and their universities about the application and selection process for EHCS and that they had applied several times for EHCS before they were eventually considered for placement (Table 1). Normally, EH graduates are allowed to choose five of their preferred placement facilities (in order of preference), and a further five choices should be submitted if they are not allocated any of the first five. An overwhelming number $(n=$ $16 ; 64 \%)$ of these participants indicated that there was no method followed for their selection for the EHCS programme, 
whereas some $(n=6 ; 24 \%)$ indicated that interviews were employed as the method of selection.

Thirteen EHCS practitioners (52\%) reported that they had been placed at rural facilities. Most of the EHCS practitioners ( $n=18 ; 72 \%$ ) agreed that their placement facilities had been prepared to receive them, and therefore they were satisfied with their sites of placement. This was contrary to their response to an open-ended question, which portrayed the state of the preparedness of the placement facilities as follows:

'There must be proper planning before EHCS practitioners arrive to avoid the challenge of having them sitting in the office whole day.' (Participant 2, EHCS practitioner, female)
'Proper plans and strategies need to be put in place prior to starting EHCS.' (Participant 4, EHCS practitioner, female)

'Community service students should be provided with accommodation at their placement facilities.' (Participant 13, EHCS practitioner,' female)

\section{Utilisation and evaluation process}

The experiences of EHCS administrators and EHCS practitioners regarding utilisation and evaluation focused on six categories, namely supervision, induction, materials and resources, utilisation, professional development and evaluation (Table 2 and Table 3).

TABLE 2: Experiences of Environmental Health Community Service administrators regarding utilisation and evaluation of Environmental Health Community Service practitioners.

\begin{tabular}{|c|c|c|c|c|c|}
\hline \multirow[t]{2}{*}{ Variables } & \multicolumn{2}{|c|}{ Yes/agree } & \multicolumn{2}{|c|}{ No/disagree } & $\begin{array}{c}\text { I do not know/neutral/ } \\
\text { no answer }\end{array}$ \\
\hline & $n$ & $\%$ & $N$ & $\%$ & $\%$ \\
\hline
\end{tabular}

\section{Supervision}

Each EHCS practitioner was allocated a supervisor or mentor

All the supervisors or mentors are qualified EHPs

The supervisors were sincere in helping the CS practitioners to fit in

The supervisors were motivating CS practitioners

The CS practitioners were at ease asking the supervisors for help

The supervisors or mentors know their work

The CS practitioners received constant supervision

$\begin{array}{cc}9 & 90 \\ 10 & 100 \\ 10 & 100 \\ 8 & 80 \\ 10 & 100 \\ 10 & 100 \\ 8 & 80\end{array}$

\section{Induction}

During the induction process, it was explained to the EHCS practitioners what was expected of them during their CS period

CS practitioners were informed about formal EH work procedures and methods of service delivery

I am of the opinion that the CS practitioners received good induction

90

100

100

80

\section{Materials and resources}

The EHCS practitioners had access to a functional telephone for work purposes

The CS practitioners had access to a functional computer for work purposes

The CS practitioners had access to relevant stationery for work purposes

The CS practitioners were provided with sufficient office space to perform their duties

Transport was provided for CS practitioners for work purposes

\section{Utilisation}

The CS professionals were rotated to gain experience

The CS practitioners were involved in $\mathrm{EH}$ issues most of the time during their CS period

The EHCS practitioners were given opportunities to work independently

The CS practitioners were productively utilised to render a more effective and efficient EH service

The work of the EHCS practitioners was exciting and challenging

1
-
-
-
-
-
1

\section{Professional development}

Because of the CS programme, the knowledge of the EHCS practitioners regarding EH service delivery has improved

Because of the CS programme, the confidence of the EHCS practitioners has improved

The EHCS practitioners have made a positive contribution in the community where they conducted their CS

The EHCS practitioners received regular feedback regarding their work performance

\section{Evaluation}

The knowledge gained by the EHCS practitioners was evaluated

It was required of the EHCS practitioners to write reports

The contribution to EH service delivery by the EHCS practitioners was evaluated

The work of the EHCS practitioners was evaluated

An exit evaluation at the end of the EHCS period was performed

10

8

9

5

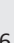

6

\section{5}

10

1

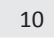

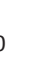

.

$\begin{array}{ll}- & - \\ - & - \\ - & - \\ - & \\ 2 & 20 \\ 1 & 10 \\ 3 & 30 \\ 4 & 40\end{array}$

3

EHCS should remain a requirement for registration with the HPCSA

10

100

70

100

80

20

EHCS, Environmental Health Community Service; NDoH, National DoH; CS, community service; EHP, environmental health practitioner; HPCSA, Health Professions Council of South Africa. 


\begin{tabular}{|c|c|c|}
\hline \multicolumn{3}{|c|}{ Frequency $(n)$} \\
\hline Yes/agree & No/disagree (\%) & $\begin{array}{l}\text { I do not know/neutral/not } \\
\text { applicable/no answer (\%) }\end{array}$ \\
\hline$\%$ & $\%$ & $\%$ \\
\hline
\end{tabular}

$\begin{array}{llr} & \boldsymbol{n} & \% \\ \text { Supervision } & & 100 \\ \text { I was allocated a supervisor } & 25 & 96 \\ \text { My supervisors were qualified EHPs } & 24 & 76 \\ \text { My supervisor was sincere in helping me to fit in } & 19 & 19 \\ \text { My supervisor was motivating me } & 23 & 92 \\ \text { I was at ease asking my supervisor for help } & 23 & 92 \\ \text { My supervisor knows his or her work } & 15 & 60\end{array}$

$\begin{array}{ll}\boldsymbol{n} & \boldsymbol{n} \\ 100 & - \\ 96 & 1 \\ 76 & - \\ 76 & - \\ 92 & 1 \\ 92 & 1 \\ 60 & 2\end{array}$

-
4
-
-
4
4
8

\section{Induction}

During my induction, it was explained what was expected of me during the CS period

I was informed about formal EH work procedures and methods of service delivery

I received a good induction

Materials and resources

I had access to a functional telephone for work purposes

I had access to a functional computer for work purposes

I had access to relevant stationary for work purposes

I was provided with sufficient office space to perform my duties

Did you have a vehicle driver's license while you were conducting your EHCS?

Transport was provided for work purposes

$\begin{array}{lccccc}11 & 44 & 8 & 32 & 6 & 24 \\ 13 & 52 & 12 & 48 & & \\ 13 & 52 & 6 & 24 & 6 & 24\end{array}$

Utilisation

I was rotated to gain experience

I was involved in $\mathrm{EH}$ issues most of the time during my CS period

I was allowed opportunities to work independently

I was productively utilised to render a more effective and efficient EH service

My work was exciting and challenging

Professional development

Because of EHCS, my knowledge of EH service delivery has improved

Because of EHCS, my confidence has improved

I have made a positive contribution in the community where I conducted my EHCS

I received regular feedback regarding my work performance

$\begin{array}{llllll}18 & 72 & 7 & 28 & - & - \\ 21 & 84 & 4 & 16 & - & - \\ 18 & 72 & 6 & 24 & 1 & 4 \\ 16 & 64 & 5 & 20 & 4 & 16 \\ 17 & 68 & 8 & 32 & - & - \\ 19 & 76 & 6 & 24 & - & -\end{array}$

Evaluation

The knowledge I gained was evaluated

It was required of me to write reports.

My contribution to $\mathrm{EH}$ service delivery was evaluated

My work performance was evaluated

I performed an exit evaluation at the end of my EHCS

EHCS should remain a requirement for registration with the HPCSA

$\begin{array}{llllll}16 & 64 & 7 & 28 & 2 & 8 \\ 21 & 84 & 1 & 4 & 3 & 12 \\ 24 & 96 & - & - & 1 & 4 \\ 23 & 92 & - & - & 2 & 8 \\ 16 & 64 & 2 & 8 & 7 & 28 \\ 24 & 96 & - & - & 1 & \\ 23 & 92 & - & - & 2 & 4 \\ 20 & 80 & 2 & 8 & 3 & 12 \\ 11 & 44 & 7 & 28 & 7 & 28\end{array}$

\section{Experiences of Environmental Health Community Service administrators}

Regarding supervision, all EHCS administrators $(n=10)$ were in agreement that all EHCS practitioners had supervisors who were qualified EHPs (Table 2). These participants further indicated that supervisors had good knowledge regarding their work, and that the EHCS practitioners were at ease about asking questions and seeking help, when needed. Although most of the EHCS administrators $(n=8 ; 80 \%)$ were convinced that the EHCS practitioners received constant and necessary supervision from their supervisors, two $(n=2$; $20 \%$ ) of these participants did not agree.

Three EHCS administrators chose to remain neutral regarding the fact that the induction process included an explanation of what was expected from EHCS practitioners during their CS. The majority of the administrators $(n=7)$ were of the opinion that the EHCS practitioners received a good induction (Table 2). Challenges that were remarked by the EHCS administrators were related to the availability of sufficient office space to perform their duties $(n=5 ; 50 \%)$, and the provision of transport for EHCS practitioners to carry out their duties $(n=4 ; 40 \%)$. In addition, one EHCS administrators suggested that:

'Proper allocation in the budget is required to fully fund all basic needs, such as stationery, computers and transport.' (Participant 4, EHCS administrator, male)

Half of the administrators $(n=5)$ opposed the fact that EHCS practitioners were rotated between different $\mathrm{EH}$ sections to gain sufficient exposure. All EHCS administrators $(n=10)$ agreed with the fact that EHCS practitioners were mostly involved in EH issues during their EHCS, and that they were productively utilised to render a more effective and efficient 
$\mathrm{EH}$ service to the communities. In addition, all EHCS administrators indicated (Table 2) that the EHCS practitioners' knowledge and confidence had improved because of sufficient exposure to $\mathrm{EH}$ aspects contained in their CS programme, and that the EHCS practitioners contributed positively to their placement facilities. The majority of EHCS administrators further agreed that the EHCS practitioners were given regular feedback about their work performance. Although the minority of these administrators indicated that an exit evaluation was conducted for the EHCS practitioners $(n=4 ; 40 \%)$, most of the EHCS administrators $(n=8 ; 80 \%)$ indicated that the contribution to EH service delivery by the EHCS practitioners was evaluated.

\section{Experiences of Environmental Health Community Service practitioners}

All the EHCS practitioners were in agreement that they had supervisors and only one indicated that his or her supervisor was not a qualified EHP. Although most of the participants indicated that their supervisors were sincere in assisting and motivating them, it was shocking to discover that $40 \%$ $(n=10)$ of the EHCS practitioners did not receive constant supervision from their supervisors (Table 3 ).

Eleven participants (44\%) indicated that, during their induction, they were informed about what was expected from them during their EHCS period. Twelve EHCS practitioners $(48 \%)$ complained that they did not receive sufficient induction training.

Twenty-one (84\%) of the EHCS practitioners reported that they had access to functional computers for work purposes. Eighteen $(72 \%)$ of the 25 respondents reported that they had access to a telephone and stationery. Seventeen of the participants $(68 \%)$ indicated that they had driver's licences when they were placed for EHCS. Nineteen of the 25 participants $(n=19 ; 76 \%)$ reported that they were provided with transport to perform their duties.

With respect to utilisation, four $(16 \%)$ participants indicated that they were rarely involved in $\mathrm{EH}$ issues during their EHCS, whereas $84 \%(n=21)$ reported that they were mostly involved in $\mathrm{EH}$ issues. Nine participants (36\%) reported that they were not rotated to other sections of their facilities to gain more experience; they were working in the same sections for the entire duration of the CS period. Most of the EHCS practitioners $(n=24 ; 96 \%)$ agreed that they were granted opportunities to work independently and $16(64 \%)$ of the participants reported that the work was challenging and exciting.

With regard to professional development, 24 (96\%) of the 25 participants reported that their knowledge improved because of exposure to EHS delivery, whereas 23 (92\%) participants reported improvement in their confidence, and 20 participants $(80 \%)$ reported that they have made a positive contribution in the communities where they conducted EHCS. Only 11 participants (44\%) stated that they received regular feedback about their work performance.

Most of the participants $(n=22 ; 88 \%)$ informed that they were required to write reports, and 17 EHCS practitioners $(68 \%)$ stated that their work performance was evaluated. Thirteen (52\%) of EHCS practitioners reported that their contribution to EH service delivery was evaluated; however, this excluded the evaluation of the knowledge that was gained by them. Most of the participants $(n=19 ; 76 \%)$ reported that they had not performed exit evaluations at the end of their EHCS programme. Only seven (28\%) participants were in support of EHCS remaining a requirement towards registration with the HPCSA as an independent EHP (Table 3).

\section{Statistical comparisons}

Statistical analysis was used to compare the experiences of EHCS administrators and EHCS practitioners regarding the selection, placement, utilisation and evaluation processes of the EHCS programme. A comparison was made between EHCS administrators and EHCS practitioners regarding the number of instances EHCS practitioners applied for placement and the number of occasions that EHCS administrators were requested to identify or create CS posts for EH graduates. No statistically significant difference was found $(p=0.0941)$. Therefore, it is accepted that the number of EHCS posts was not sufficient for the employment of all $\mathrm{EH}$ graduates who applied for the identified CS posts. A statistically significant difference was found ( $p=0.0253)$ between responses of EHCS practitioners (mean = 1.67; standard deviation $=0.56$ ) and EHCS administrators (mean = 1.20; standard deviation $=0.42$ ) regarding the utilisation of EHCS practitioners to render an effective and efficient EHS; therefore, it is accepted that EHCS practitioners were given ample opportunity to render an effective and efficient EHS. A statistically significant difference was found (0.036) between responses of EHCS practitioners $(n=4 ; 16 \%)$ and EHCS administrators $(n=4 ; 40 \%)$ regarding the exit evaluation. It is therefore accepted that there is no association of exit evaluations between EHCS practitioners and EHCS administrators.

\section{Conclusion}

The HPCSA reported that the placement of EH graduates for CS has been a serious challenge for the DoH since 2007, and therefore this challenge has had a negative impact on the EHS delivery, especially in a country faced with a quadruple burden of disease (Cele et al., 2012). The devolution of EHS from the provincial health district to the municipal health sphere has caused permanent damage regarding the number of advertised posts for EHCS in the EC province, declining from 53 to 3 posts.

The major problems that were identified included maladministration of EHCS, which related to the lack of consistency of communication during the organisation of the 
EHCS programme; a decline in the number of EHCS posts in the EC province which led to shortage of human resources; inadequate provision of material resources for conducting EHCS; lack of induction and inconsistent supervision of EHCS practitioners; and lack of evaluation of the successes or challenges of the EHCS programme. The most alarming resource problem was related to the lack of access to stateowned vehicles for some EHCS practitioners during their EHCS period.

\section{Recommendations}

It is clear from the findings of the study that EHCS practitioners who were placed in the EC province, and the EHCS administrators who were organising EHCS during 2013-2016, faced numerous challenges. Based on the findings of this study, the following recommendations are suggested:

1. The NDoH should work with the South African Local Government Association (SALGA) to develop a framework for EHCS. The framework will outline the requirements and procedures of post-identification in all the provinces and their municipalities, and it will be a guide to local, provincial, and national government on EHCS implementation.

2. All provinces and their municipalities should open EHCS posts for EH until they all meet the national norm, which is at least one EHP for every 10000 people (as advocated by the World Health Organization and in the EH National Policy, Section 8.1). This could be achieved by obligating all the municipalities to submit their EHCS posts as per the requirement stipulated in the $\mathrm{EH}$ policy for all provinces and municipalities and $\mathrm{NDoH}$ to provide a budget for the effective implementation of EHCS.

3. Provincial health departments and their municipalities should strengthen their partnership with universities to ensure the effective administration of bursaries to $\mathrm{EH}$ students, and then the recruitment and retention strategy for EHCS practitioners using bursary obligation will be achieved.

4. Every effort should be made to place all the EH graduates in underserved rural areas, to achieve the real purpose of EHCS, which is addressing the needs of communities in underserved rural areas.

5. Each EHCS practitioner should be allocated a senior mentor for the year to whom he or she should be accountable.

6. A thorough and informative orientation opportunity should be pre-arranged by the DoH for all new EHCS practitioners when they arrive at their placement facilities. They should be informed about the particulars of the location, the organogram of the organisation, including their duties and obligations. It should also allow them an opportunity to meet their managers and fellow staff members. This should ensure that all EHCS practitioners are informed about their duties and what is expected of them during the CS year.

7. The provision of guidelines that address and ensure extensive and continuous supervision and support to the
EHCS practitioners would positively contribute to the improvement in the provision of quality healthcare services. This should also include the proper and regular (quarterly) rotation of EHCS practitioners to other divisions.

8. It is advised that the provincial department of health and relevant municipalities compile an information leaflet, clearly stating the objectives and expectations of EHCS, as well as indicating which services should be rendered, and which need to be improved during their EHCS year, to ensure that all EHCS practitioners are informed about what is expected from them before they commence their EHCS programmes.

9. It is recommended that a quarterly review of the EHCS placement be conducted by a professional team consisting of relevant EHCS coordinators and representatives. An audit tool can be designed, and regular audit evaluations could be showcased.

10. Adequate and efficient equipment, facilities and accessibility to resources (which include transport, stationery, offices, computers and Internet access) should be provided at each EHCS placement facility.

The Minister of Health and the Workforce Management: Statutory Service Placements Directorate in the National $\mathrm{DoH}$ for $\mathrm{EH}$ and EC provincial $\mathrm{DoH}$ are advised to address the contents of this article, and use the suggestions relating to EHCS allocations to rectify these complex and critical problems.

\section{Acknowledgements Competing interests}

The authors have declared that no competing interest exists.

\section{Authors' contributions}

P.M. was the student conducting the study under the supervision and leadership of Prof. I.S. Human and Prof. P.E. Melariri. Both I.S.H. and P.E.M. contributed equally to the success of this study and P.M. graduated with a master's degree in Environmental Health in April 2018.

\section{Funding information}

This research received no specific grant from any funding agency in the public, commercial or not-for-profit sectors.

\section{Data availability statement}

Data sharing is not applicable to this article as no new data were created or analysed in this study.

\section{Disclaimer}

The views and opinions expressed in this article are those of the authors and do not necessarily reflect the official policy or position of any affiliated agency of the authors. 


\section{References}

Beyers, B. (2013). Experiences of CS practitioners who are deployed at a rura health facility in the Western Cape. Retrieved from http://etd.uwc.ac.za/xmlui/ handle/11394/3321

Cele, A., Chaka, J., Nemakonde, D., \& Mukhola, S. (2012). Environmental health 2012 Newsletter for the Professional Board for Environmental Health Practitioners. Pretoria: Health Professions Council of South Africa.

De Haan, M. (1996). The Health of Southern Africa (7th edn.). Cape Town: Juta.

Harvey, B.M., \& Pillay, A.L. (2006). The experiences of the first South African CS clinical psychologists. South African Journal of Psychology, 36(2), 259-280. https://doi. org/10.1177/008124630603600204

Hatcher, A.M., Onah, M., Kornik, S., Peacocke, J., \& Reid, S. (2014). Placement, support, and retention of health professionals: National, cross-sectional finding from medical and dental CS officers in South Africa. Human Resources for Health. Retrieved from https://doi.org/10.1186/1478-4491-12-14

Khan, N.B., Knight, S., \& Esterhuizen, T. (2009). Perceptions of and attitudes to the compulsory community service of therapists in KwaZulu-Natal. South African Journal of Communication Disorders, 56(1), 17-22. https://doi.org/10.4102/sajcd. v56i1.189

Maseko, L.J. (2012). Factors that influence choice of placement for CS among occupational therapists. South African Journal of Occupational Therapy, 44. Retrieved from http://www.scielo.org.za

Ndaba, B.J. (2013). Lived experiences of newly qualified professional nurses doing community service in midwifery section in one Gauteng hospital. Health Studies Dissertation, University of South Africa, Pretoria.

Nel, P., Werner, A., Poisat, P., Sono, T., Ngalo, N., \& Du Plessis, A. (2014). Human resources management (9th edn.). Oxford: Oxford University Press.
Reid, S. (2002). Community service for health professionals in South African: Health review 2002. Durban: Health Systems Trust.

Reid, S.J., \& Conco, D. (1999). Monitoring the implementation of CS. In South African health review 1999. Durban: Health Systems Trust. Retrieved from http://www. hst.org.za/uploads/files/chapter17_99.pdf

South Africa. DoH. (2004). The National Health Act 61 of 2003. Government Gazette 469(26595). Retrieved from http://www.nsw.gov.au/sites/default/files/ Government-Gazette2-December.pd f\#page $=15$

South Africa. DoH. (2009). Regulations defining the scope of the profession of environmental health regulation R.698, Under Section 33(1) and section 61(2) of the Health Professions Council of South Africa as amended. Pretoria: Government Printer.

South Africa. DoH. (2013). National Environmental Health Policy. (37112)3-43. Pretoria: Government Printer.

South Africa. DoH. (2015a). Community Service Letter for 2016 Allieds.pdf. Pretoria: Government Printer.

South Africa. DoH. (2015b). National environmental health norms and standards for premises and acceptable monitoring standards for environmental health practitioners regulation R.39561, in terms of Section 21(2) (b)(ii) of the Nationa Health Act, 2003 (Act No. 61 of 2003) as amended. Pretoria: Government Printer.

South Africa. DoH. (2016). Response from DOH Community Service Issues 4th Aug 16.pdf filename= UTF-8"Response from DOH - Community Service Issues (4th Aug 16).pdf. Pretoria: Government Printer.

Tarimo, E. (1991). Towards a healthy district: Organizing and managing district health systems based on primary health care. Geneva: World Health Organization.

Wranz, E.S. (2011). Compulsory community service for speech-language and hearing therapy professionals: Readiness, reality and readjustment. Unpublished master's minor dissertation, March, pp. 1-49. 